\title{
Risk factors associated with hospitalization and evolution in kidney transplant patients with COVID-19: A single-center retrospective cohort study
}

\author{
Isabel Beneyto Castelló ${ }^{1}$ (D), Elena Moreno Maestre ${ }^{2}$ (D), David Ramos Escorihuela ${ }^{1}$ (D), Jordi Espí Reig ${ }^{1}$ (D), Ana Ventura Galiano ${ }^{1}$ (iD, \\ María Ramos Cebrián ${ }^{1}$ (iD), Marta Moreno Espinosa ${ }^{1}$ (iD), Pablo González-Calero Borrás ${ }^{1}$ (iD), Julio Hernández Jaras ${ }^{1}$ (iD) \\ ${ }^{1}$ Kidney Transplant Unit, Department of Nephrology, Hospital Universitario La Fe; Valencia, España \\ ${ }^{2}$ IIS La Fe - Medical Research Institute Hospital La Fe; Valencia, España
}

\section{ABSTRACT}

Background: The SARS-CoV-2 infection has had a major impact on kidney transplant patients. Our single-center experience aims to analyze the risk factors for affected patient hospitalization and predictors of worse clinical outcome on admission.

Material and methods: A retrospective cohort study with kidney transplant patients with positive PCR for SARS-CoV-19 between March $16^{\text {th }} 2020$ and February $11^{\text {th }} 2021$ was conducted. Demographic characteristics and clinical and laboratory information on admission was collected and analyzed to assess risk factors related to patient hospitalization and disease evolution.

Results: Seventy-six kidney transplant recipients diagnosed with COVID-19 were included and divided into hospitalized ( $n=48$ ) and non-hospitalized ( $n=28$ ) patients. Two hospitalized patients were not taken into account for the analysis due to a lack of data, and the remaining patients were divided into mild-moderate $(n=25)$ and severe pneumonia $(n=21)$. Lasso and multivariate logistic regression demonstrated that age (OR 1.041, $p=0.039$ ) and hypertension (OR 4.177, $p=0.040$ ) were risk factors for hospitalization, while time after transplant (OR 0.993, $p=0.029)$ decreases the probability of being hospitalized. Analyses also revealed that $\mathrm{SpO} 2 \leq 92 \%$ on admission $(\mathrm{OR} 8.954, p=0.026)$ and overweight/obesity (OR 13.453, $p=0.001$ ) were related to a worse evolution and severe pneumonia among hospitalized recipients. Seven patients died due to COVID-19 complications.

Conclusion: Age and hypertension are risk factors for hospitalization among positive COVID-19 patients, while time after transplant decreases the probability of being hospitalized. Overweight/obesity and levels of SpO2 $\leq 92 \%$ on admission were the main risk factors that could help to predict the severity of COVID-19 disease in our series.

Key Words: COVID-19, kidney transplantation, nephrology, risk factors

(C) 2021 Portuguese Journal of Nephrology \& Hypertension. Published by Publicações Ciência \& Vida This is an open access article under the CC BY-NC-ND license (http://creativecommons.org/licenses/by-nc-nd/4.0/).

\section{INTRODUCTION}

Since the declaration of the Coronavirus Disease 2019 (COVID-19) pandemic in March 2020, countries world-wide have registered a large number of cases in different waves that have brought their health-care systems to the limit of saturation.

Several factors such as advanced age, obesity, diabetes mellitus, hypertension, and cardiovascular pathology have been associated with the disease severity in the general population. Against this backdrop, solid organ transplant patients are a major risk group, given the high prevalence of these factors in addition to their chronic immunosuppressive state ${ }^{1,2}$. The mortality rates among kidney transplant patients vary in different reports, but are high especially in the elderly and in the early post-transplant period ${ }^{3,4}$. A report of the Spanish Registry shows differences in overall mortality between the first
(March-June) and second (July-December) wave (27.4\% vs $15.1 \%$ ) but similar rates in critical patients ${ }^{5}$.

The aim of this study is to analyze the risk factors for hospitalization and the predictors of worse clinical outcome on admission in our kidney transplant patients affected by COVID-19 during the pandemic thus far.

\section{SUBJECTS AND METHODS}

\section{Study design and participants}

This was a retrospective cohort study that included kidney transplant recipients with COVID-19 treated at the transplant unit of La Fe Hospital in Valencia. We included all adult kidney transplant recipients with a 
functioning allograft who tested positive for SARS-CoV-2 between March $16^{\text {th }} 2020$ and February $11^{\text {th }} 2021$. Patients were classified into several groups for analysis: a first division based on the need for patient hospitalization and a second division among hospitalized patients regarding their evolution and the development of severe pneumonia.

\section{Data collection}

Demographic, clinical, laboratory, and comorbidity data were extracted retrospectively from electronic medical records at our center. A total of 17 patients were hospitalized in other centers, and their information was collected by phone or their hospital records were accessed electronically, when possible. Clinical and laboratory information of two patients could not be collected. SARS-CoV-2 diagnosis was based on the polymerase chain reaction (PCR) test from the nasopharyngeal swab.

\section{Statistical analysis}

Categorical variables were summarized with counts and percentages, while quantitative variables included minimum-maximum, means (standard deviation) and medians with Interquartile Range (IQR), where appropriate. Due to our small sample size and in order to avoid overfitting, variable selection via Lasso regularization was applied. After multicollinearity and potential outliers had been checked, the penalty factor (lambda) that produces the lowest possible mean squared error in our data was calculated through cross-validation. Lambda at 1 standard error of the minimum was chosen, giving a simpler and parsimonious model. Selected variables were then included in a multivariate logistic regression model and interpreted in terms of odds ratio (OR) and $95 \%$ confidence intervals. A P-value of $<.05$ was considered significant. Model fit was checked through residual diagnostics. Analyses were performed using R Statistical Software (version 4.0.4).

\section{RESULTS}

\section{Demographic and clinical characteristics}

Since the pandemic outbreak in March 2020 to February $11^{\text {th }} 2021$, 76 kidney transplant recipients were diagnosed with COVID-19 (Figure 1). Out of 76 infected patients, 49 (64.5\%) were male while 27 (35.5\%) were female, between 24 and 81 years of age, with mean 57.5 and standard deviation 13.9. Regarding blood type, the most common among patients were type $A$ and $O(n=31$ [40.8\%] and $n=27$ [35.5\%], respectively) followed by type $B(n=10[13.2 \%])$ and $A B(n=3[3.9 \%])$. Remaining cases ( $n=5[6.6 \%]$ ) were not available.

Causes of kidney disease included glomerular disease $(n=22$ [28.9\%]), (Autosomal Dominant Polycystic Kidney Disease (ADPKD) $(n=13[17.1 \%])$, hypertension $(n=11[14.4 \%])$, interstitial $(n=10$ [13.2\%]), unknown ( $n=10$ [13.2\%]) and other causes ( $n=10$ [13.2\%]).

Hypertension was the most common comorbidity affecting $n=63$ [82.9\%] of patients, followed by overweight/obesity ( $n=36$ [47.4\%]), diabetes $(n=29[38.1 \%])$ and cardiovascular disease $(n=22[28.9 \%])$.

\section{Figure 1}

COVID-19 case-evolution in kidney transplant

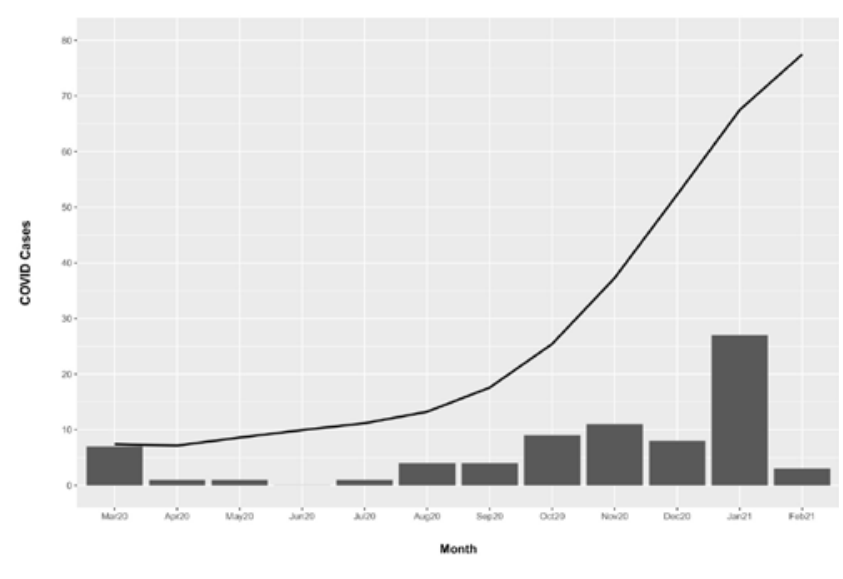

Time to diagnosis of COVID-19 after transplantation ranged from 4 months to 396 (33 years) with median 90 and IQR (40.3-162), while the vast majority of patients ( $n=51[67.1 \%]$ ) were diagnosed during the first decade after transplantation. Maintenance immunosuppression therapy followed a standard guideline, including steroids, tacrolimus and antimetabolite (mycophenolate mofetil or mycophenolic acid) for most of the patients ( $n=72$ [94.7\%]), with those treated with mTOR inhibitor $(n=4[5.3 \%])$ and Cyclosporine $(n=2[2.6 \%])$ being a minority. The almost absence of difference regarding immunosuppressive regimen led to the exclusion of this variable in the statistical analysis.

\section{Clinical outcome and Laboratory results}

The most common symptoms were fever $(n=45[59.2 \%])$, cough $(n=36[47.4 \%])$, dyspnea ( $n=17$ [22.4\%]), asthenia ( $n=15$ [19.7\%]), myalgia $(n=13[17.1 \%])$ and gastrointestinal symptoms $(n=13$ [17.1\%]. A total of 38 patients (50\%) developed pneumonia; 12 (15.8\%) remained asymptomatic and 48 (63.2\%) were hospitalized. Table I shows baseline characteristics of the patients in terms of hospitalization.

Of the 48 hospitalized patients, laboratory and clinical information during admission could not be obtained for two. Henceforth, data will refer to the 46 remaining subjects.

Time from COVID-19 diagnosis to hospitalization ranged from zero (being diagnosed the same day of admission) to 26 days. The patients' main symptoms at the moment of hospitalization were cough $(n=30$ [65.2\%]) and fever $(n=29[63 \%])$, followed by dyspnea ( $n=15$ [32.6\%]) and asthenia $(n=13[28.3 \%])$. A total of 19 patients $(41.3 \%)$ needed oxygen support on admission, while 13 of them (28.3\%) had an oxygen saturation (SpO2) rate $\leq 92 \%$. The differentiating cut-off point of a low oxygen saturation at $\leq 92 \%$ is based on Severinghaus equations, where the author establishes a relationship between $\mathrm{SpO} 2$ saturation and $\mathrm{p} 02, \mathrm{mmHg}^{6}$. We consider hypoxia as the decrease of $\mathrm{pO} 2$ below 60 $\mathrm{mmHg}$, which corresponds to a $\mathrm{SpO} 2$ saturation of $90.7 \%$. Thus, to be above that limit and as a cut-off point to initiate supplemental oxygen therapy, the limit of SpO $2 \leq 92 \%$ was established. Concerning 


\section{Table I}

Patients' demographic and clinical characteristics

\begin{tabular}{|c|c|c|}
\hline & $\begin{array}{l}\text { Non-Hospitalized } \\
\qquad(\mathrm{N}=\mathbf{2 8})\end{array}$ & $\begin{array}{l}\text { Hospitalized } \\
\qquad(\mathrm{N}=48)\end{array}$ \\
\hline \multicolumn{3}{|l|}{$\begin{array}{l}\text { Demographic information } \\
\operatorname{Sex}(N, \%)\end{array}$} \\
\hline Male & $17(60.7 \%)$ & $32(66.7 \%)$ \\
\hline Female & $11(39.3)$ & $16(33.3 \%)$ \\
\hline Age (mean $\pm S D$, years) & $52.1 \pm 14.8$ & $60.7 \pm 12.5$ \\
\hline $\begin{array}{l}\text { Post-transplant time to diagnosis } \\
\text { (Median-IQR 25-75, months) }\end{array}$ & 131 (49.7-188) & $73(37.5-121.7)$ \\
\hline \multicolumn{3}{|l|}{ Cause of CKD (N, \%) } \\
\hline Glomerular & $6(21.5 \%)$ & $16(33.3 \%)$ \\
\hline ADPKD & $4(14.3 \%)$ & $9(18.8 \%)$ \\
\hline Hypertensive nephropathy & $2(7.1 \%)$ & $9(18.8 \%)$ \\
\hline Interstitial & $7(25 \%)$ & $3(6.2 \%)$ \\
\hline Unknown & $2(7.1 \%)$ & $8(16.7 \%)$ \\
\hline Other & $7(25 \%)$ & $3(6.2 \%)$ \\
\hline \multicolumn{3}{|l|}{ Comorbidities (N, \%) } \\
\hline Hypertension & $19(67.9 \%)$ & $44(91.7 \%)$ \\
\hline Overweight/Obesity & $13(46.4 \%)$ & $23(47.9 \%)$ \\
\hline Diabetes mellitus & $7(25 \%)$ & $22(45.8 \%)$ \\
\hline Cardiovascular disease & $7(25 \%)$ & $15(31.2 \%)$ \\
\hline
\end{tabular}

SD - Standard Deviation; IQR - Interquartile Range; CKD - Chronic Kidney Disease; ADPKD - Autosoma Dominant Polycystic Kidney Disease.

patient evolution, 21 (45.7\%) developed severe pneumonia, while the remaining 25 (54.3\%) had a better evolution (including from mild to moderate pneumonia, or a mild to moderate clinical manifestation without respiratory symptoms). Hospitalization time ranged from one day to 93 , with a considerable percentage $(60.9 \%)$ being hospitalized for a period of less than two weeks.

Regarding laboratory measures on admission, interest focused on creatinine (mg/dL), C-reactive protein (CRP) (mg/L), lymphocyte $\left({ }^{x_{1}} 10^{3} /\right.$ $\mu \mathrm{L})$, leucocyte $\left({ }^{\mathrm{x}} 10^{3} / \mu \mathrm{L}\right)$ and D-dimer $(\mathrm{ng} / \mathrm{mL})$. Thus, creatinine levels in the total amount of hospitalized patients showed a median of 1.6 $\mathrm{mg} / \mathrm{dL}$ and IQR (1.2-2.5 mg/dL), while leucocyte presented a median of $5.9 \times 10^{3} / \mu \mathrm{L}$ and IQR $\left(4.5-7 \times 10^{3} / \mu \mathrm{L}\right) .63 \%$ of the patients had lymphopenia $\left(<1^{x} 10^{3} / \mu \mathrm{L}\right)$, with the median for all patients being $0.8^{x} 10^{3} /$ $\mu \mathrm{L}$ and IQR (0.5-1.2 $\left.\times 10^{3} / \mu \mathrm{L}\right)$. Median and IQR for CRP and D-dimer were $55.5 \mathrm{mg} / \mathrm{L}(19.4-91.1 \mathrm{mg} / \mathrm{L})$ and $600 \mathrm{ng} / \mathrm{mL}(383-838.2 \mathrm{ng} / \mathrm{mL})$, respectively. Table II shows baseline, clinical, and laboratory characteristics between both groups.

A small percentage of recipients experienced acute renal failure during hospitalization ( $n=8$ [17.4\%], three of whom required hemodialysis. None of the patients experienced acute rejection or allograft loss. Eleven patients $(23.9 \%)$ met the criteria for admission to the intensive care unit (ICU), and seven died.

\section{Treatment of COVID-19, immunosuppression adjustment and oxygen therapy}

Treatment changed between the waves with more frequent use of ritonavir/lopinavir ( $n=3[6.5 \%])$, hydroxychloroquine $(n=6[13 \%])$,

\section{Table II}

Demographic characteristics, clinical manifestation, and laboratory results according to COVID-19 disease evolution

\begin{tabular}{|c|c|c|}
\hline & $\begin{array}{c}\text { Moderate } \\
\text { evolution }(N=25)\end{array}$ & $\begin{array}{l}\text { Severe pneumonia } \\
\qquad(\mathrm{N}=\mathbf{2 1})\end{array}$ \\
\hline \multicolumn{3}{|l|}{ Demographic information } \\
\hline \multicolumn{3}{|l|}{ Sex $(N, \%)$} \\
\hline Male & $16(64 \%)$ & $15(71.4 \%)$ \\
\hline Female & $9(36 \%)$ & $6(28.6 \%)$ \\
\hline Age (mean $\pm S D$, years) & $55.92 \pm 12.3$ & $64.95 \pm 10.6$ \\
\hline \multicolumn{3}{|l|}{ Comorbidities (N, \%) } \\
\hline Hypertension & $22(88 \%)$ & $20(95.2 \%)$ \\
\hline Overweight/Obesity & $5(20 \%)$ & $17(81 \%)$ \\
\hline Diabetes mellitus & $6(24 \%)$ & $14(66.7 \%)$ \\
\hline Cardiovascular disease & $4(16 \%)$ & $10(47.6 \%)$ \\
\hline \multicolumn{3}{|l|}{ Clinical information } \\
\hline \multicolumn{3}{|l|}{ Symptoms on admission ( $\mathrm{N}, \%)$} \\
\hline Cough & $14(56 \%)$ & $16(76.2 \%)$ \\
\hline Fever & $14(56 \%)$ & $15(71.4 \%)$ \\
\hline Dyspnea & $6(24 \%)$ & $9(42.9 \%)$ \\
\hline Asthenia & $7(28 \%)$ & $6(28.6 \%)$ \\
\hline Need for oxygen support $(\mathrm{N}, \%)$ & $4(16 \%)$ & $15(71.4 \%)$ \\
\hline $\mathrm{SpO} 2 \leq 92 \%(\mathrm{~N}, \%)$ & $2(8 \%)$ & $11(52.4 \%)$ \\
\hline \multicolumn{3}{|c|}{ Laboratory results (median-IQR 25-75) } \\
\hline Creatinine $(\mathrm{mg} / \mathrm{dL})$ & $1.56(1.2-2)$ & $2(1.3-3)$ \\
\hline 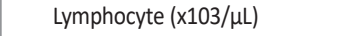 & $0.8(0.6-1.2)$ & $0.8(0.4-1)$ \\
\hline 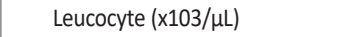 & $5.4(4.3-6.7)$ & $6.4(4.9-8.9)$ \\
\hline C-reactive protein (CRP) (mg/L) & $29.9(9.1-75.8)$ & $70.8(47.9-122.5)$ \\
\hline D-dimer (ng/mL) & $460(342-782)$ & $666(526-857)$ \\
\hline
\end{tabular}

SD - Standard Deviation; SpO2 - blood oxygen saturation levels.

and azithromycin ( $n=16$ [34.8\%]) in the first wave, and with more frequent use of remdesivir ( $n=2$ [4.3\%]) and steroids ( $n=31$ [67.4\%]) in the second. The patients experiencing cytokine storm received tocilizumab in the initial stages but not in the next waves ( $n=3$ [6.5\%]). High steroid doses were used as treatment for pneumonia and hyper-inflammatory state. Regarding immunosuppression adjustment, tacrolimus and antimetabolite were reduced or discontinued in most cases $(n=35$ (76.1\%), with complete withdrawal of the immunosuppressive treatment in 9 patients (19.6\%). Asymptomatic patients did not receive specific drugs against COVID-19 and did not require immunosuppression adjustment. In patients with pneumonia, the reduction of immunosuppressive treatment was made according to the published recommendations of the DESCARTES Group ${ }^{7}$. Treatment and immunosuppression adjustment differences in line with patients' severity are included in Table III.

Ventilatory support via nasal cannula with reservoir was provided to patients whose $\mathrm{SpO} 2$ rate $\leq 92 \%$, aiming at a SpO2 rate towards $96 \%$. If this was insufficient, a high-flow nasal cannula or Venturi mask was provided. Non-invasive mechanical ventilation was the next step in order to consider when respiratory failure continued, unless immediate intubation criteria existed. Thus, a total of 22 patients (47.8\%) needed oxygen support throughout the hospitalization period. Conventional oxygen therapy was the most common ( $n=17$ [77.3]), using a high and low-flow nasal cannula ( $n=6[27.3 \%]$ and $n=7$ [31.8\%], respectively) and Venturi mask $(n=4[18.2 \%])$. Five patients $(22.7 \%)$ required intubation, all of whom had presented a $\mathrm{SpO} 2$ rate $\leq 92 \%$ at admission. 


\section{Table III}

Immunosuppression adjustment and infection treatment

\begin{tabular}{l||c||c} 
& $\begin{array}{c}\text { Moderate } \\
\text { evolution } \\
\text { (N = 25) }\end{array}$ & $\begin{array}{c}\text { Severe } \\
\text { pneumonia } \\
\text { (N=21) }\end{array}$ \\
\hline Immunosuppression adjustment (N, \%) & & \\
$\quad$ Antimetabolite or tacrolimus readjustment & $17(68 \%)$ & $18(85.7 \%)$ \\
Complete immunosuppression withdrawal & $2(8 \%)$ & $7(33.3 \%)$ \\
Treatment of infection (N, \%) & & \\
Ritonavir-lopinavir & $1(4 \%)$ & $2(9.5 \%)$ \\
Hydroxychloroquine & $3(12 \%)$ & $3(14.3 \%)$ \\
Azithromycin & $9(36 \%)$ & $7(33.3 \%)$ \\
Remdesivir & $2(8 \%)$ & $0(0 \%)$ \\
Tocilizumab & $1(4 \%)$ & $2(9.5 \%)$ \\
Increased steroids & $15(60 \%)$ & $16(76.2 \%)$ \\
\end{tabular}

\section{- Risk factors associated with hospitalization and COVID-19 evolution}

Variables included in Table I, except chronic kidney disease (CKD) cause, were considered as potential hospitalization predictors and therefore included in Lasso. After a parsimonious model with three variables was selected by $L 1$ regularization, multivariate logistic analysis revealed that age and hypertension were predictors for hospitalization, while time after transplant was related with a lower need for hospital assistance (Table IV).

Regarding COVID-19 evolution in hospitalized patients, summarized variables in Table II and Table III were included in Lasso as possible indicators, excluding symptoms on admission (as they are beyond the scope of this study) and need for oxygen support (due to its strong correlation with $\mathrm{SpO} 2 \leq 92 \%$ ). After SpO2 $\leq 92 \%$ and overweight/ obesity were selected, multivariate logistic regression analysis revealed that both variables are associated with a worse evolution among hospitalized patients (Table IV).

\section{Table IV}

Multivariate logistic regression analysis of the parameters related to hospitalization and COVID-19 evolution

\begin{tabular}{l||c||c} 
& Odds Ratio (Cl 95\%) & p-value \\
\hline Hospitalization Risk Factors & & \\
$\quad$ Age & $1.041(1.002-1.085)$ & 0.039 \\
Post-transplant time to diagnosis (months) & $0.993(0.987-0.999)$ & 0.029 \\
Hypertension & $4.177(1.103-18.133)$ & 0.040 \\
Disease Evolution Risk Factors & & \\
SpO2 $\leq 92 \%$ & $8.954(1.485-82.148)$ & 0.026 \\
Overweight/Obesity & $13.453(3.023-77.231)$ & 0.001 \\
SpO2 - blood oxygen saturation levels. & & \\
\end{tabular}

\section{DISCUSSION}

This is a retrospective cohort study that reflects the experience of a single center faced with the impact of COVID 19 disease on its kidney transplant patients.
Considering our 1500 functioning allografts and 76 infected patients, this equals an incidence of $5 \%$, similar to the global incidence of $4.8 \%$ reported by the Spanish Society of Nephrology (S.E.N. $)^{8}$ and to the $6.1 \%$ reported in the general population ${ }^{9}$. None of these patients had received a COVID-19 vaccine at the time of the study, since the vaccination rollout in our recipients was initiated in April 2021.

As shown in Figure 1, the first peak was reached at the end of March, beginning with the first wave that lasted until May, and a total of 9 cases was reported. From then, incidence stayed low until the start of the second wave at the end of summer, reaching the highest number of cases in November. Despite the fact that a larger number of cases was recorded during the second wave $(n=29)$, these cases were distributed fairly equally between months, mostly due to the severe restrictions that were kept in place in Spain, which resulted in greater control of the pandemic during that wave. However, at the beginning of December and coinciding with a national holiday as well as the advent of Christmas with less severe restrictions, a third and more virulent wave emerged, which reached its peak in January. Thirty-eight cases were reported during that time.

The need for hospitalization in our study was $63.2 \%$ of all affected patients. The mortality rate was $14.5 \%$ a lower percentage than in other published series, which is above $25 \%{ }^{10,11}$. Only 12 (15.8\%) diagnosed patients remained asymptomatic. In the overall series, symptoms such as fever, cough and dyspnea are the most common at presentation and hospital admission percentages are similar in other published reports ${ }^{11,12}$.

In our analysis, older age and hypertension were the main risk factors for hospitalization among positive COVID-19 patients, while the probability of being hospitalized decreased with time after transplantation. It should be highlighted that about $67.1 \%$ of our patients were at least ten years after their transplant. Advanced age and COVID-19 infection in the first months were associated with severe disease and high mortality in previous series ${ }^{13,14}$. We also analyzed in our hospitalized patients which factors on admission could be related to a worse evolution and severe pneumonia. Among them, only SpO2 $\leq 92 \%$ on admission (OR 8.954, $p=0.026$ ) and overweight/obesity (OR 13.453, $p=0.001$ ) were predictors of a worse evolution. These observations are similar to the published results from registry series ${ }^{5,15}$. The relationship with low oxygen rates and poor outcomes has also been described in several studies ${ }^{16,17}$.

This retrospective cohort study has some limitations. First, the sample size is small, lowering the study power which may lead to false-positives and overestimated effect sizes. Further, the limited sample size does not allow the division into a train and test set to check the model performance, which would have strengthened the results. However, this should not be a limitation in order to provide useful data which may help focus on high-risk patients.

On the other hand, this single-center experience provides the advantage of a follow-up and homogeneous treatment criteria. 


\section{Acknowledgments and funding}

We would like to recognize the effort made by healthcare personnel around the world during the health crisis caused by SARS-CoV-2 disease.

Disclosure of potential conflicts of interest: none declared.

\section{References}

1. Richardson S, Hirsch JS, Narasimhan M, et al. Presenting characteristics, comorbidities, and outcomes among 5700 patients hospitalized with COVID-19 in the New York City Area. JAMA. 2020;323(20):2052-2059.

2. Pascual J, Melilli E, Jiménez-Martín C, et al. COVID-19-related mortality during the first 60 days after kidney transplantation. Eur Urol. 2020;78(4):641-643. https://doi.org/10.1016/j.eururo.2020.06.036

3. Huang C, Wang Y, Li X, et al. Clinical features of patients infected with 2019 novel coronavirus in Wuhan, China. Lancet. 2020;395(10223):497-506.

4. Crespo M, Mazuecos A, Rodrigo E, et al. Respiratory and gastro- intestinal COVID-19 phenotypes in kidney transplant recipients. Transplant. 2020;104(11):2225-2233. https://doi.org/10.1097/ TP. 0000000000003413

5. Villanego F, Mazuecos A, Pérez-Flores IM, et al. Predictors of severe COVID-19 in kidney transplant recipients in the different epidemic waves: Analysis of the Spanish Registry. Am J Transplant. 2021 Mar 23. doi: 10.1111/ajt.16579.

6. Severinghaus JW. Simple, accurate equations for human blood 02 dissociation computations. J Appl Physiol. 1979;46:599-602.

7. Maggiore U, Abramowicz D, Crespo c et al. How should I manage immunosuppression in a Kidney transplant patient with COVID-19? An ERA-EDTA DESCARTES expert opinión. Nephrol Dial Transplant. 2020;35:899-904. doi: 10.1093/ndt/gfaa130

8. Registro S.E.N. COVID-19. Informe 20. Spanish Society of Nephrology. https://mailchi.mp/senefro/ registro-epidemiolgico-vhc-vhb-vih-1315046 Accessed October 25, 2021.

9. Informe no 66. Situación de COVID-19 en España a 17 de febrero de 2021. Equipo COVID-19. RENAVE. CNE. CNM (ISCIII). https://www.isciii.es/QueHacemos/Servicios/VigilanciaSaludPubliCaRENAVE/EnfermedadesTransmisibles/Documents/INFORMES/Informes\%20COVID-19/ INFORMES\%20COVID-19\%202021/Informe\%20COVID-19.\%20N\%C2\%BA\%2066_17\%20de\%20 febrero\%20de\%202021.pdf Accessed October 25, 2021.

10. Fernández-Ruiz M, Andrés $A$, Loinaz $C$, et al. COVID-19 in solid organ transplant recipients: a single-center case series from Spain. Am J Transplant. 2020;20(7):1849-1858.

11. Cravedi P, Mothi S, Azzi Y, et al. COVID-19 and kidney transplantation: Results from the TANGO International Transplant Consortium. Am J Transplant 2020 Nov;20(11):3140-3148. doi: 10.1111/ajt.16185.
12. Raja MA, Mendoza MA, Villavicencio A, et al. COVID-19 in solid organ transplant recipients: A systematic review and meta-analysis of current literature. Transplant Rev (Orlando). 2021 Jan;35(1):100588. doi: 10.1016/j.trre.2020.100588.

13. Crespo M, Pérez-Sáez MJ, Redondo-Pachón D, et al. COVID-19 in elderly kidney transplant recipients. Am J Transplant. 2020;20(10):2883-2889. doi:10.1111/ a ajt16096.

14. Pascual J, Melilli E, Jiménez-Martín C et al.. COVID-19-related Mortality During the First 60 Days After Kidney Transplantation. Eur Urol. 2020 Oct;78(4):641-643. doi: 10.1016/j.eururo.2020.06.036.

15. Caillard S, Anglicheau D, Matignon M. An initial report from the French SOT COVID Registry suggests high mortality due to COVID-19 in recipients of kidney transplants Kidney Int 2020 Dec;98(6):1549-1558. doi: 10.1016/j.kint.2020.08.005.

16. Mejía F, Medina C, Cornejo E, Morello E, Vásquez S, Alave J. Oxygen saturation as a predictor of mortality in hospitalized adult patients with COVID-19 in a public hospital in Lima, Peru. PLoS One. 2020;15 doi: 10.1371/journal.pone.0244171

17. Petrilli CM, Jones SA, Yang J, et al. Factors associated with hospital admission and critical illness among 5279 people with coronavirus disease 2019 in New York City: prospective cohort study. BMJ. 2020;369:m1966

\section{ORCID}

Isabel Beneyto Castelló (iD) 0000-0002-8433-3448

Elena Moreno Maestre (iD) 0000-0002-0714-4205

David Ramos Escorihuela (iD) 0000-0002-2272-9682

Jordi Espí Reig (iD 0000-0003-2443-1035

Ana Ventura Galiano (iD) 0000-0002-5105-8726

María Ramos Cebrián iD 0000-0003-1027-2432

Marta Moreno Espinosa (iD 0000-0002-8096-5632

Pablo González-Calero Borrás (iD) 0000-0001-9544-5608

Julio Hernández Jaras (iD 0000-0003-1250-1550

\section{Correspondence to:}

Elena Moreno Maestre

IIS La Fe - Medical Research Institute Hospital La Fe

Avenida de Fernando Abril Martorell 106, Torre A, 7ạ , 46026 Valencia, España E-mail: elena_moreno@iislafe.es 